\title{
Towards a semantics for mass expressions derived from gradable expressions
}

David Nicolas

\section{(2) OpenEdition \\ 1 Journals}

\section{Electronic version}

URL: http://journals.openedition.org/rlv/1857

DOI: $10.4000 /$ rlv. 1857

ISSN: 1958-9239

\section{Publisher}

Presses universitaires de Vincennes

\section{Printed version}

Date of publication: 1 December 2010

Number of pages: 163-198

ISBN: 978-2-84292-264-1

ISSN: 0986-6124

\section{Electronic reference}

David Nicolas, «Towards a semantics for mass expressions derived from gradable expressions », Recherches linguistiques de Vincennes [Online], 39 | 2010, Online since 01 December 2014, connection on 21 April 2019. URL : http://journals.openedition.org/rlv/1857 ; DOI : 10.4000/rlv.1857 
Recherches Linguistiques de Vincennes 39 - 2010 - p. 163-198

\title{
David NICOLAS \\ Institut Jean Nicod (EHESS - ENS - CNRS)
}

\section{TOWARDS A SEMANTICS FOR MASS EXPRESSIONS DERIVED FROM GRADABLE EXPRESSIONS}

\begin{abstract}
What semantics should we attribute to mass expressions like wisdom and love, which are derived from gradable expressions (wise, to love)? We first examine how these expressions are used, then how they are interpreted in their various uses. We show in particular that, just like with ordinary concrete mass nouns (wine, furniture), sentences where they appear are liable to distributive, collective, and intermediate construals. We then propose a model to account for these data, in which derived mass expressions denote instances of properties. The model is general enough to apply both to concrete and derived mass nouns. This establishes that mass nouns have a uniform semantics. Another feature of the account is that, to explain the gradability of mass expressions, it makes use of degrees and measure functions only when these are overtly expressed, in expressions like a lot of wisdom and two litres of wine.
\end{abstract}

\section{KEYWORDS}

Mass nouns, nominalization, properties, gradability, distributivity. 
The topic of this paper is the following ${ }^{1}$ : what semantics should we attribute to mass expressions derived from gradable expressions, i.e. from adjectives and verbal expressions that accept the comparatives more and less:

(1) Julie showed more wisdom than Fred.

(2) Julie loved Fred less than Tom.

From the adjective wise and the verb to love, English has formed the nominal expressions wisdom and love. Other examples of such pairs include sad $\rightarrow$ sadness, hostile $\rightarrow$ hostility, to respect $\rightarrow$ respect, to work $\rightarrow$ work.

Semantic studies about mass nouns have concentrated on concrete mass nouns like wine or furniture. (For reviews of the literature, see Pelletier \& Schubert, 1989; Krifka, 1991; and Nicolas, 2002a.) But they have said nothing concerning mass expressions like wisdom or love. This raises an important question: are derived mass nouns a separate species of mass nouns, with their own semantic properties? Or can a general account be proposed, which would work both for concrete mass nouns and derived ones?

Studying the semantics of derived mass nouns forces us to take a more general stance than when focusing on concrete mass nouns alone. Several issues arise:

-Reference: concrete common nouns can be used in definite descriptions, where they seem to refer to entities of various types. Do derived mass nouns refer to something when they are used in definite descriptions? And if so, what do they refer to?

- Distributive, collective, and intermediate construals: sentences with concrete mass nouns or plurals may receive so-called distributive, collective, and intermediate construals. Is it also the case with derived mass nouns?

- Gradability: in all the major parts of speech, we find expressions that are gradable, i.e. expressions that accept the comparatives more and less. How should we account for gradability?

- Nominalization: what is the semantic effect of nominalization? In other words, how is the semantics of a derived mass noun linked to that of the gradable adjective or verb it is derived from?

In what follows, we propose a model for the semantics of derived mass nouns, in which each of these issues is given a certain solution. Our aim is not so much to argue extensively for these solutions, but rather to sketch a general model that is both coherent and plausible. (By doing so, at the very

1. For comments and criticisms, I would like to thank Francis Corblin, Paul Egré, Brendan Gillon, Jacques Jayez, Friederike Moltmann, Philippe Schlenker, Benjamin Spector, Arnim von Stechow, Lucia Tovena, and anonymous reviewers. Barring subsequent slight revisions, this paper was completed by February 2006. For various reasons, its publication will have taken a long time. 
least, we want to make clear what theoretical choices have to be made before a semantics for derived mass nouns can be proposed.) We show that some of the proposals that have been made when focusing on concrete mass nouns can also be applied when considering derived mass nouns. This, we hold, is neither a futile exercise nor a trivial result: nothing guarantees whether this can be done successfully. Models that have been proposed for the semantics of mass nouns are general enough only if they apply to concrete mass nouns and to derived mass nouns alike. Whether this is so must be established, not assumed. ${ }^{2}$

The paper is organized as follows. We begin by identifying the distribution of the class of nominal expressions that we are interested in. We then look at the interpretations that these nouns can receive in their various uses. These first two sections are thus descriptive: they aim at describing what the data concerning use and interpretation are, in a theory neutral way. We then look for a model that can account for these data.

\section{The uses of mass expressions derived from gradable expressions}

We look at cases in which a gradable expression (like a gradable adjective or a gradable verbal expression) gives rise, through nominalization, to a nominal expression that behaves morphosyntactically like a mass noun (like wine or furniture). ${ }^{3}$ This means that the nominal expression can be used in the following ways.

2. The work presented in this paper builds on previous research by the author (Nicolas, 2002a; 2002b; 2004). In Nicolas (2004), the object of study was mass nouns derived from gradable adjectives. Here, it is, more generally, mass nouns derived from gradable (adjectival and verbal) expressions. The empirical coverage is thus extended. The data concerning how derived mass nouns are understood in their various uses is also presented in much more detail in section 2. In particular, it is shown for the first time that derived mass nouns are susceptible to distributive, collective, and intermediate construals (modulo lexical constraints, knowledge of the world and context of speech). The theoretical coverage is also largely extended in section 2, concerning notably reference, distributive, collective, and intermediate construals, and gradability.

3. In many languages, including English, most common nouns divide into two morphosyntactic subclasses, mass nouns and count nouns (Gillon, 1992). A defining characteristic of mass nouns, like milk, is that they are invariable, while count nouns, like cat, can be used in the singular and in the plural. Depending on the language, this basic morphosyntactic difference between the two types of noun is often supplemented by differences as to the determiners they can combine with. Thus, in English, mass nouns can be used with determiners like much and a lot of, but neither with one nor many. On the contrary, count nouns can be employed with numerals like one and determiners like many, but not with much.

It is of course well known that mass nouns can, in certain contexts, be used as count nouns (You should take a hot milk with some honey), and vice versa (You will find a lot of 
First, it can appear together with a possessive phrase: Julie's wisdom, the love of Julie for Tom, or in a definite nominal expression with a relative (non-possessive) phrase: the wisdom that Julie showed on that occasion, the love that Julie felt for Tom.

Second, it can appear together with an indefinite, mass determiner like a lot of or much:

(3) Julie showed a lot of wisdom in that occasion.

(4) Julie did not feel much love for Tom.

Third, it can appear in comparative constructions, its grammatical number being singular:

(5) Julie showed more wisdom than Fred did on that occasion.

(6) Julie had more love for Tom than for Fred.

Fourth, it can be used without any determiner, in sentences that are not comparative:

Wisdom is rare.

Julie encountered love.

Fifth, it is in general invariable in grammatical number. It seems hard, for instance, to talk of wisdoms or loves for Fred. Doing so requires a special context and induces a change in meaning. Finally, it may sometimes be used together with a count determiner, notably in expressions of the form $[a(n)+$ adjective + nominal expression]: a great wisdom / an incredible love. (In particular, for process verbs like to work, it is well known that nominalization often gives rise both to a mass noun that denotes the process, and to a count noun that denotes the result of the process as in: This is such a great work.)

Can the class of expressions that give rise to mass expressions be characterized more precisely? Since a mass expression is gradable (it can be combined with comparatives when employed normally in the singular), this must also be the case with the original expression. Thus, if the original expression is an adjective, it must be a gradable one (wiser / less wise).

rabbit around here). One then talks of conversion. Conversion is a common grammatical possibility, whereby a member of a grammatical category is used in the morphosyntactic environment characteristic of another grammatical category. For instance, proper names can be used as common nouns: The professor has two Picassos in his class (cf. Gillon, 1992; Kleiber, 1994). Uses of nominal expressions like love for Fred with a count determiner are cases of conversion, from mass to count.

Nota bene: some common nouns, like immortality, are not gradable and hence are neither mass nor count: *a lot of immortality, *many immortalities. 
By contrast, a non-gradable adjective will generally give rise to a nominal expression that is not a mass expression: immortal is not gradable (*more / *less immortal), hence neither is immortality (*more / *less immortality). ${ }^{4}$ Likewise, if the original expression is a verbal expression, it must be gradable, i.e. accept the comparatives more and less. Now, telic verbal expressions are not gradable: they cannot be modified by the comparatives more and less without being coerced to an atelic interpretation. Telic verbal expressions are verbal expressions that accept duration prepositional phrases like in two hours and reject phrases like for two hours (Vendler, 1957; Verkuyl, 1993). The predicate expressed by a telic verbal expression is satisfied only if the event it describes has reached a set terminal point (Verkuyl, 1993). We thus understand why a telic predicate is not gradable: a telic predicate is either satisfied or not, but it cannot be satisfied more in one case than in another. One cannot eat a cake more than another cake (unless eat a cake is coerced into an atelic meaning, where it describes any part of an event of eating a cake). Hence, if a mass noun is derived from a verbal expression, the verbal expression must be atelic. The verbs to love and to work are indeed atelic, giving rise to the mass nouns love and work.

Even though the condition that the original expression be gradable is generally sufficient, it is not always so. Thus, a gradable adjective like tall gives rise to the noun tallness, which is not gradable (*more / *less tallness). Also, a particular form of nominalization that often gives rise to a mass expression may fail to do so in certain cases. For instance, gradable verbs like love, respect, and work give rise to phonologically identical mass expressions. But the mass expression that corresponds to a verb like walk is not walk but walking. We will focus on the cases in which the original gradable expression does give rise to a mass expression.

In the next section, we will see what interpretations mass nouns like wisdom and love receive in their various uses. We want to be theory-neutral: the goal is to characterize the intuitions of ordinary speakers concerning how these nouns can be understood in their various uses. It is in section 3 that we will see how these intuitions can be accounted for theoretically.

\footnotetext{
4. This is true in most cases, but not always. Thus, in French, the adjective mortel ('mortal') is not gradable, cf. *plus mortel ('more mortal'), but the derived noun mortalité ('mortality') seems to be gradable:

Il y a eu plus de mortalité sur les routes cette année que l'an passé.

'There has been more mortality on the roads this year than last year.'

This illustrates a general fact about morphology: often, it is not possible to state necessary and/or sufficient conditions relating the semantic properties of a derived word and those of the expression it is derived from.
} 


\section{The interpretations of mass expressions derived from gradable expressions}

\subsection{The interpretation of possessive and definite uses}

Take sentences like:

(9) Julie's wisdom attracted Tom.

(10) Julie's love for Fred attracted Tom.

What do they mean? The subject of each sentence (Julie's wisdom, Julie's love for Fred) seems to refer to, describe, or assert the existence of, some entity that is said to have attracted Tom. But what kind of entity? Our intuitions, as ordinary speakers, are not very clear, be it concerning the meaning of these sentences, or the kind of entity referred to by their subject. In fact, several possibilities come to mind. In order to elucidate what they are, we examine how these sentences may be paraphrased.

A word of caution, though. Paraphrases will give us some indications concerning the meaning of these expressions and what they refer to (if they really refer to something). However, as is well known, paraphrases are a delicate matter. They may notably correspond to only some aspect of the meaning of what they paraphrase. We will have to bear this in mind in section 3, when discussing how to account theoretically for our intuitions concerning the interpretations of derived mass nouns.

According to a first intuition, the sentences above may be paraphrased as: the fact that Julie was wise attracted Tom; the fact that Julie loved Fred attracted Tom. The entity referred to by a nominal expression like Julie's wisdom might thus be a fact.

According to a second intuition, the sentences may be paraphrased as: Tom was attracted by how wise Julie was; Tom was attracted by how much Julie loved Fred. Another, less natural type of paraphrase (which uses a technical term, degree) points in the same direction: the degree at which Julie was wise attracted Tom; the degree at which Julie loved Fred attracted Tom. The entity referred to might therefore be a degree of wisdom or love.

According to a third intuition, the sentences can be paraphrased as: how Julie was wise attracted Tom; how Julie loved Fred attracted Tom. Another equivalent paraphrase is: the way in which Julie was wise attracted Tom; the way in which Julie loved Fred attracted Tom. The entity referred to might thus be an instance (a concrete manifestation) of a property or relation ${ }^{5}$, that is, the particular way in which a property or relation manifests itself in a

5. To simplify exposition, we will often talk of instances of properties, rather than using the more cumbersome instances of properties or relations. (Nota bene: the formal 
given individual. (On instances of properties, see Mulligan et al., 1984; and Lowe, 1998, as well as section 3.2 below.)

Let us now consider other predicates than to attract and vary the position of the derived nominal expression (putting it for instance in the object position of a transitive verb). We find that some predicates license one type of paraphrase but not the others.

Thus, predicates like to acknowledge and to be a fact can combine with expressions like Julie's love for Fred, license a paraphrase in terms of facts, but not the other types of paraphrases:

(11) It took Tom a long time, but he finally acknowledged Julie's wisdom. ${ }^{6}$

(12) Julie's love for Fred is a fact.

The first sentence can be understood as: Tom finally acknowledged the fact that Julie was wise. But it cannot be paraphrased as: Tom finally acknowledged the degree at which Julie was wise, or as: Tom finally acknowledged the way in which Julie was wise. Likewise for the sentence Julie's love for Fred is a fact. Predicates like acknowledge and is a fact seem to require that the referent of Julie's wisdom or Julie's love for Fred be a fact. ${ }^{7}$

Second, we find that there are predicates like to describe and to admire that can combine with expressions like Julie's wisdom and Julie's love for Fred, license a paraphrase in terms of an instance of a property, but not the other types of paraphrases:

(13) Tom described Julie's wisdom.

(14) Tom admired Julie's love for Fred.

distinction between properties and relations is not important: properties can be seen as a special case of relations, namely relations that have only one argument.)

6. Adapted from a similar example given in French by Van de Velde (1995: 141).

7. Notions like factives and factive contexts have been discussed in the literature (see, e.g. Kiparsky and Kiparsky, 1971; Delacruz, 1973). So has Vendler's idea that gerunds of the form her performing the song would refer to facts (Vendler, 1968; Asher, 1993). However, we have found very few predicates that, with expressions like Julie's love for Fred, license a paraphrase in terms of facts and clearly refuse a paraphrase in terms of instances of properties or relations. Consider for example factive predicates like surprise, bother and attract. These predicates are said to be factive because, when they take a clausal subject, they presuppose that the embedded sentence be true. If the sentence That Julie loved Fred surprised Tom is true, this entails that the sentence embedded in the subject Julie loved Fred) is also true. Nonetheless, in general, these predicates accept many things as the referent of their subject, including ordinary people (Julie), property instances (the love that Julie felt for Fred) and facts (the fact that Julie loved Fred). 
In these sentences, an expression like Julie's wisdom cannot be understood as meaning something like: the degree at which Julie was wise, or: the fact that Julie was wise. These predicates seem to license only a paraphrase in terms of an instance of wisdom, where the expression may be paraphrased as: the way in which Julie was wise.

Are there predicates that select for the paraphrase in terms of degrees? It seems so, at least at first sight:

(15) Julie's wisdom exceeded Fred's.

(16) Julie's love for Fred was greater than her love for Tom.

These sentences seem to tell us something concerning how wise Julie was and how much Julie loved Fred.

Finally, we may also note the following uses:

(17) ?Julie's wisdom lasted a week.

(18) Julie's sadness lasted a week.

(19) Julie's love for John lasted half a year.

The contrast between the first two sentences comes from the fact that, while sadness is typically a temporary property, wisdom is typically a permanent one. However, this contrast is far from absolute, as we can easily imagine a context where wisdom becomes temporary, e.g. if it is due to the effect of a drug. ${ }^{8}$

And as observed at the beginning of this section, there are predicates, like to attract and to surprise, which allow for any of these paraphrases:

(20) Julie's wisdom attracted Tom.

(21) Julie's love for Fred surprised Tom.

\subsection{The interpretation of indefinite and comparative uses}

Consider now uses of the nominal expression together with an indefinite determiner characteristic of mass nouns like much or a lot of:

(22) Julie showed much wisdom.

(23) Julie felt a lot of love for Fred.

These sentences may be paraphrased as: Julie was very wise; Julie loved Fred a lot. They thus express something concerning how wise Julie was, and how much Julie loved Fred. (We could also say, in a less natural paraphrase, that

8. Some researchers have seen the possibility of combination with lasted a week as evidence that expressions like Julie's sadness refer to a state (cf. Asher, 1993). 
they express something concerning the degree at which Julie was wise, and the degree at which Julie loved Fred.)

Something similar is observed when the noun is used in a comparative construction:

(24) Julie showed more wisdom than Fred.

(25) Julie felt more love for Fred than for Tom.

They can be paraphrased as: Julie was wiser than Fred; Julie loved Fred more than Tom. They thus compare and order certain entities with respect to the extent at which they possess a certain property.

\subsection{The interpretation of bare uses}

Nominal expressions like wisdom or love can also occur bare, without any determiner, outside of comparative constructions:

(26) Julie encountered love.

(27) Wisdom is rare.

Acceptable paraphrases might be something like: Julie encountered someone who loved her, and: it is rare that someone be wise. It is noteworthy that no systematic procedure seems to be able to produce such paraphrases automatically. (In a less natural way, we could also say: Julie encountered an instance of love from a certain individual, and: instances of wisdom are rare.)

\subsection{The interpretation of count uses}

Consider now a sentence like:

(28) Julie had an incredible love for Fred.

This is a case of conversion, where the mass noun love is used as a count noun. Its interpretation seems to parallel that of a comparable sentence, where love is replaced by a concrete mass noun like wine:

(29) Julie bought an incredible wine.

This sentence says that Julie bought an instance of wine that is of a particular type, to which the predicate expressed by the adjective applies. Similarly, the sentence that concerns love says that the love felt by Julie is of a particular type, to which the predicate expressed by the adjective applies. 


\subsection{Distributive, collective, and intermediate construals with plural arguments}

Take an expression like Julie's wisdom. The proper name Julie may be said to be the argument of the noun wisdom. Similarly in the case of an expression like Julie's love for Fred, Julie and Fred may be said to be the arguments of the noun love.

Above, we have only considered cases where the arguments were singular: the expression Julie in the case of Julie's wisdom, and the expressions Julie and Fred in the case of Julie's love for Fred. We did so in order to avoid unnecessary complications. However, derived mass nouns can of course have plural arguments: the wisdom of Julie and Fred, these girls' love for these boys. We now want to determine whether this makes a difference, i.e. whether the presence of a plural argument gives rise to more possibilities of interpretation.

It is well known that sentences with plurals and concrete mass nouns may receive so-called collective, distributive, and intermediate construals (cf. notably Link, 1983; Landman, 1989; Gillon, 1987, 1992, 1996). To explain what these construals are, we start with the case of plurals. Consider a sentence whose subject is a plural expression:

(30) Alice, Julie, and Mary carried this desk.

It may be true if Alice, Julie, and Mary, together, carried the desk: this is the collective construal. It may be true if each of the women, by herself, carried the desk: this is the distributive construal. It may also be true if, say, Alice and Julie, together, carried the desk, and Mary, by herself, also carried the desk: this is an intermediate construal.

As shown by Gillon (1996), a simple clause may receive collective, distributive, and intermediate construals as long as at least one of the arguments of the verb is a plural expression. The plural argument may be the subject, the object or the indirect object of the verb, or the object of a prepositional phrase complementing the verb. Thus,

Bill shuffled the face cards and the non-face cards

may be understood as: Bill shuffled the face cards with the non-face cards, or for instance as: Bill shuffled the face cards and Bill shuffled the non-face cards.

The specific meanings of the verbal expression and its arguments, combined with knowledge of the world and context of speech, may render a type of construal implausible. Consider an attributive sentence with a gradable adjective, like sad:

These men are sad. 
A distributive construal is strongly favored: the sentence is true because each man is sad. This is typically the case with gradable adjectives. However, a collective construal is also possible, when the property expressed by the adjective can be attributed to a group as a whole. Thus, watching a basketball game of the Pistons of Detroit, one may say:

(33) These men are strong tonight.

The sentence may be true because the group of men, as a whole, is strong (while each man, by himself, is not), or it may be true because each of the men is strong. Moreover, suppose the Pistons are playing the Pacers from Indiana. Then the sentence These men are strong tonight may be used to refer to all the men on the playground, and it may be made true because the Pistons, as a team, are strong, and the Pacers, as a team, are also strong.

Collective, distributive and intermediate construals also arise within complex noun phrases, independently of verbs. They can obtain with any prepositional phrase. The expression the suitcases in the bedroom and the vestibule is typically understood in a distributive manner, where it is equivalent to the suitcases in the bedroom and the suitcases in the vestibule (since a suitcase cannot be at the same time in the bedroom and in the vestibule). On the other hand, the expression the children of John, Mary and Fred may receive an intermediate construal, and denote the children that John and Mary have together and the children of Fred.

What precedes also applies to concrete mass nouns, as the following examples testify:

(34) The wine costs fifteen euros.

(35) The furniture is in the bedroom and the vestibule.

(36) The furniture in the bedroom and the vestibule

(37) The furniture of these people

A sentence with a concrete mass noun may receive collective, distributive, and intermediate construals (modulo the meaning of the particular lexical items composing the sentence, context of speech and knowledge of the world). And so may a noun phrase containing a prepositional group, like the furniture of these people.

Let us now show that the above facts are mirrored when we focus on the interpretation of derived mass nouns. It seems that one can appropriately use a noun phrase like the sadness of these men only when each man is sad; that is, a distributive construal of the noun phrase is strongly favored. This is typically the case with derived mass nouns. However, an expression like the strength of these men may be used when each man is strong, or when the group of men, 
considered as a whole, is strong. It may thus receive a distributive construal, or a collective construal. It may also receive an intermediate construal, if, say, these men denotes the Pistons from Detroit and the Pacers from Indiana. A collective or an intermediate construal is possible when the property expressed by the derived mass noun can be attributed to a group as a whole.

What we just said can be substantiated in more detail by considering complete sentences. This will allow us, in particular, to control whether the types of paraphrases discussed in section 2.1 are all available. If it were not the case, this would constitute a significant fact, which an appropriate theoretical account would need to explain. We saw that a sentence like Tom was attracted by Julie's wisdom may be paraphrased in three ways: in terms of facts (Tom was attracted by the fact that Julie was wise), in terms of degrees (e.g. Tom was attracted by how wise Julie was), and in terms of instances of properties (e.g. Tom was attracted by the way in which Julie was wise). As we see below, these types of paraphrases are all attested when the argument of the derived noun is a plural expression.

Sentences like the following may indeed be paraphrased in terms of facts:

(38) The sadness of the girls surprised Fred.

'The fact that these girls were sad surprised Fred.'

(39) The indignation of the journalists at these news had no effect.

'The fact that the journalists were indignant at these news had no effect.'

(Nota bene: other types of paraphrases are also available.) Paraphrases in terms of degrees are accessible with sentences like:

(40) The sadness of the boys was extreme.

'These boys were extremely sad.'

'The degree at which each boy was sad was extreme.'

(41) The strength of these men was incredible.

'These men were incredibly strong.'

'The degree at which these men were strong was incredibly high.'

And the sentences below may be paraphrased in terms of instances of properties:

(42) John remembered the nervousness that Lucy and Mary had shown that evening.

'John remembered how Lucy and Mary had been nervous that evening.'

'John remembered the way in which Lucy and Mary had been nervous that evening.'

(43) The sadness of these boys was terrible to see.

'How these boys were sad was terrible to see.'

'The way in which these boys were sad was terrible to see.' 
This completes our description of the data concerning the uses and interpretations of derived mass nouns. Let us now see how these data can be accounted for.

\section{Theoretical foundations for a semantics of derived mass nouns}

\subsection{Methodological considerations}

How can we account theoretically for the data presented above? As said in the introduction, a number of issues must be addressed, which can be labelled as follows: reference; distributive, collective, and intermediate construals; gradability; and link between noun and adjective or verb.

From a methodological point of view, we think it is best to consider these issues independently from one another. That is, each type of phenomenon should be first considered on its own, to see what is needed in order to account for it. Then of course, we should see how the various theoretical ingredients can be integrated with one another. In particular, to find out what is the link between the semantics of a verb or adjective and the semantics of the noun derived from it, we should assess independently what the semantics of each is.

Before doing so, let us consider briefly two issues that have not yet been mentioned, because we think that they are peripheral: genericity, and Davidsonian versus classical frameworks. Concerning genericity, we follow Gillon (1990). He defends the view that bare uses of mass nouns or plurals are indefinite uses (whose interpretation is an existential one), and that what is called genericity corresponds to a variety of independent phenomena, which are neither restricted, nor specially attached, to bare uses. For alternative views, see for instance Carlson (1977) and Wilkinson (1991). Whatever the theory, it must account for the existential interpretations of bare mass nouns and plurals. Following Gillon, we take these to be basic.

Let us mention just one point here. It has been remarked that bare plurals, depending on context, may receive a universal or an existential interpretation:

(44) Mohan loves puppies.

'Mohan loves all the puppies that exist.'

(45) Mohan owns puppies.

'Mohan owns some of the puppies that exist.'

The factor determining the construal of the bare plural seems to be extragrammatical (Gillon, 1990: 153-155). It rests on the fact that one believes that, while someone may love all puppies, no one owns, or is likely to own, all puppies. Gillon suggests a unified explanation of the two cases. In each case, the sentence asserts that there are puppies such that Mohan Vs them (i.e. loves them or owns them). What the relevant set of puppies is depends on the meaning 
of the verb, context of speech, and knowledge of the world. The universal construal of the first sentence concerns a set of puppies that includes all the puppies that exist. The existential construal of the second sentence concerns a restricted set of puppies, which includes only some of the puppies that exist. However, an existential construal of the first sentence is clearly possible, and a universal interpretation of the second sentence is possible: after all, it could be that there are puppies, corresponding to all the puppies that exist, such that Mohan owns them. This phenomenon is akin to the possibility of domain variation observed with noun phrases like all the puppies. The sentence Mohan loves all the puppies can be understood either as meaning: Mohan loves all the puppies that exist, or: Mohan loves all the puppies of a contextually determined subset of the set of all the puppies that exist.

Let us now consider the question of Davidsonian versus classical frameworks for predicates like verbs and adjectives. In a classical framework, a verb like to love denotes a function from couples $(\mathrm{x}, \mathrm{y})$ to truth-values: $x$ loves $y$ is true if and only if love $(\mathrm{x}, \mathrm{y})$. The arguments of the function love are those that are mentioned in the sentence $x$ loves $y$. In a (neo)-Davidsonian framework, the verb denotes a function from triples $(\mathrm{e}, \mathrm{x}, \mathrm{y})$ to truth-values: $x$ loves $y$ is true if and only if $\exists$ e love $(\mathrm{e}, \mathrm{x}, \mathrm{y})$, that is, if and only if there exists an eventuality (in this case, a state) of $x$ loving $y$. The function love receives an additional, eventuality argument, which is not mentioned in the sentence $x$ loves $y$. This is done in order to account for adverbial modification, certain types of anaphora, nominalization, and verbs of perception (Parsons, 1990). However, in his survey of the discussions on this topic, Landman (2000: ch. 1, and ch. 3, section 3.4) reaches a number of negative conclusions. First, neither anaphora (ch. 1, section 1.5) nor nominalization (ch. 1, section 1.4) nor perception verbs (ch. 1, section 1.6) offer by themselves evidence in favor of a Davidsonian framework. For Landman (2000: viii), the only robust piece of evidence is provided by the facts about adverbial modification, the so-called permutation and drop entailments. Second, Landman (ch. 3, section 3.4) concludes that even this does not force a decision to adopt either a classical or a Davidsonian framework for verbs and adjectives. To these negative conclusions, let us add the following remarks. First, concerning adverbial modification, only certain adverbs authorize permutation and drop entailments, contrary to what one should expect in a Davidsonian framework. Landman himself draws a parallel between adverbs and adjectives. It is well known that, with respect to similar permutation and drop entailments, adjectives come into various classes: intersective, subsective, and privative. However, most theorists have proposed to account for these differences in terms of meaning postulates (Partee, 2005), rather than with a hidden variable. The same solution can be adopted in the case of adverbs. Second, using a hidden variable for eventualities to account for adverbial modification yields various difficulties, as shown by Moltmann 
(2007, section 5). For instance, in a Davidsonian framework, how should one account for Mary dances slowly very elegantly, where, on one understanding of the sentence, what is very elegant is not Mary's dancing simpliciter, but Mary's dancing slowly? Third, adopting a Davidsonian framework not only for verbs, but also for adjectives, soon yields a proliferation of eventuality arguments, as shown by Larson and Segal (1995: ch. 12). And fourth, we hold that Davidsonianism obscures, rather than illuminates, the semantic effect of nominalization. As said above, to find out what is the link between the semantics of a verb or adjective and the semantics of the noun derived from it, we should assess independently what the semantics of each is. In a (neo)Davidsonian framework, this is prejudged: an expression like the love of $x$ for $y$ is said to refer to the eventuality that is existentially quantified over in the sentence $x$ loves $y$. For all these reasons, we will use a classical framework for verbs and adjectives in what follows.

Let us come back to the issues that are our main concern: reference; distributive, collective, and intermediate construals; and gradability. These are central issues that must be dealt with when proposing a semantics for mass nouns, be they concrete or derived. As we will show below, dealing with each issue brings a certain element in the model. Reference is accounted for by having the noun denote entities of a certain type. Distributive, collective, and intermediate construals are accounted for by rules for the interpretation of simple clauses and complex noun phrases. And gradability is accounted for by associating to the predicate an ordering relation and additional mechanisms for certain types of use. When we focus on concrete mass nouns, we come up quite naturally with such answers. When we concentrate on derived mass nouns, we may also propose answers of the same type. Indeed, the data presented in section 2 show striking parallelisms between verb or adjective and derived mass noun with respect to gradability, and distributive, collective, and intermediate construals. Whatever mechanisms are responsible for gradability and these construals with gradable verbs or adjectives, these mechanisms must be somehow inherited by the derived noun. What about reference? Do derived mass nouns refer, and if so, to what entities? It is to these questions that we now turn. Once these questions are settled, we will see how to account for distributive, collective, and intermediate construals with concrete mass nouns and plurals (section 3.4); and how to account for the gradability of various types of predicates (section 3.5). Then, in section 4, we will see how these theoretical ingredients mesh together, and provide a complete semantics for derived mass nouns. 


\subsection{Is reference illusory?}

Consider again two examples of section 2.1:

Julie's wisdom attracted Tom.

Julie's love for Fred attracted Tom.

Grammatically, their subjects are definite descriptions. Now, in the case of nouns that concern material entities, definite descriptions (Julie's wine, Julie's cat) are paradigmatic cases of singular terms. A singular term is an expression that refers to (or asserts the existence of) a single entity. So, are Julie's wisdom and Julie's love for Fred singular terms? That is, does each refer to a single entity? Given that Julie's wine and Julie's cat are singular terms, one would be tempted to answer yes.

However, according to researchers like Dummett (1973: ch. 4), we should not do so: uses of expressions like Julie's wisdom are mere façons de parler. Indeed, derived mass nouns, contrary to genuine singular terms, fail to supply what Frege called a criterion of identity. Dummett explains this notion as follows: "If we are to understand an expression as standing for an object, then we must be able, in Frege's vivid phrase, to recognize the object as the same again: we must, that is, know under what circumstance some other term will stand for the same object » (1973: 73). A singular term is an expression that supplies, as part of its meaning, a criterion of identity for the entities it applies to. But, according to Dummett, expressions like wisdom and love do not supply such a principle. We do not know what entity would be named by Julie's wisdom, so that we may recognize that the same entity is referred to in another circumstance. If we were talking of Julie's wisdom twenty years ago, when she was ten years old, and if we again talk of her wisdom now, when she is thirty, are we talking of the same thing, of the very same entity? For Dummett, we do not know, and this question is in fact nonsense.

Dummett's position is based on certain ontological intuitions and semantic considerations. He finds it obvious that there cannot exist an entity like Julie's wisdom. According to him, we do not know what it could be, in particular since we have no idea what criterion of identity could decide when two "wisdoms" are the same or different. Dummett also presupposes that a genuine singular term must supply a criterion of identity.

However, these intuitions and considerations are subject to debate. For instance, Mulligan et al. (1984) and Lowe (1998) accept instances of properties in their ontologies. (Instances of properties have also been called moments, tropes, abstract particulars, individual accidents, or modes. Mulligan et al. prefer the term moment, while Lowe prefers the term mode.) An instance of a property (or relation) is a particular way in which a property is instantiated in some entity, a concrete manifestation of that property in this 
entity (Lowe, 1998: 78). An instance of a property is thus a dependent particular: a particular that depends for its existence on the existence of other particulars. As a particular, it is rooted in space, time and the causal order. Consider a solid material object, such as a rubber ball. It will be shaped in a particular way and colored in a particular way at any given time. Suppose the rubber ball is spherical (with a certain radius of curvature) and red (with a certain hue). The ball's sphericity is then an instance of the property of sphericity, and the ball's redness is an instance of the property of redness. Likewise, if Julie is wise, the property of wisdom will be instantiated in Julie in a particular way. Julie's wisdom is then the particular and concrete way in which the property of wisdom manifests itself in Julie. Lowe (1998: 78-83) insists that one of the characteristics of instances of properties is that they lack a definite criterion of identity.

So, which position should semanticians adopt? In fact, semanticians need not base their semantic theories on ontological considerations. They may feel fundamentally unconcerned by the metaphysical question « What does really exist? », and be uncommitted concerning what answer should ultimately be given to it. After all, it seems that ordinary people do manage to refer to persons, towns and rivers, even though philosophers disagree as to whether persons, towns and rivers really exist or not. It is in questions like the following that semanticians are interested. How are such and such expressions used? How are they interpreted in their various uses? And what is the best way to account for these uses and interpretations? So semanticians may adopt the following methodological principle: unless there is convincing evidence to the contrary, expressions that seem to be used and interpreted in the same way should be modeled with the same syntactic and semantic mechanisms. Thus, a semantic theory may say that Julie's wisdom, just like Julie's wine, refers to (or describes, or asserts the existence of) a certain entity. This entity therefore appears in the metalanguage of the theory. At the same time, semanticians may remain completely uncommitted as to whether, in the final, scientific analysis of how the world is structured, there really exist such entities or not.

The attitude just advocated is one of metaphysical neutrality. It is close to the idea put forth by Bach (1986) and Asher (1993), that semanticians should study natural language metaphysics, that is, identify the entities that natural language refers to and quantifies over. It is compatible with some attitudes that are metaphysically more committed. Thus, it is compatible with a realist position (like Lowe's): one that claims real existence for the entity referred to by an expression like Julie's wisdom, e.g., an instance of a property, a concrete manifestation of wisdom in Julie.

It may also be compatible (under some interpretation) with what has been called a fictionalist attitude: given its grammatical form, a sentence containing the expression Julie's wisdom purports to refer to an entity; but it is 
in fact typically used to convey a different proposition, which may be captured by a suitable paraphrase. As shown by Rosen (2005), this kind of attitude may be ascribed to Jeremy Bentham, who developed the notion of a fictional entity. "A real entity is an entity to which, on the occasion and for the purposes of discourse, existence is really meant to be ascribed. A fictional entity is an entity to which, though by the grammatical form of the discourse employed in speaking of it, existence is ascribed, yet in truth and reality, existence is not meant to be ascribed" (Bentham, 1842, vol. 8: 195). For example, when we say that John is under an obligation to do this, the word obligation is a common noun, so it purports to refer to some entity. But, according to Bentham, no one would suggest that in making such a claim we commit ourselves to the view that in reality there exists a thing, an obligation, under which John is. Given its literal meaning, the sentence John is under an obligation to do this purports to refer to a certain entity, an obligation. But speaker and hearer know that the sentence is typically used to convey a different proposition, which may be captured by a suitable paraphrase, viz., John will suffer pain or loss of pleasure unless he does this. This paraphrase "may be regarded as giving, not the literal meaning of the original claim, but rather the sober truth [...] the original is typically used to convey" (Rosen, 2005: 53).

However, the attitude of metaphysical neutrality is clearly incompatible with (what has been called) a reductionist attitude. For a reductionist, a sentence like Tom admired Julie's wisdom does not even purport to refer to a certain entity. The sentence is directly understood in terms of a suitable paraphrase, viz., Tom admired how Julie was wise. This paraphrase gives, and exhausts, the meaning of the original sentence. This seems to be the stance of Dummett (1973: 72).

Now, as Alston (1958) and Varzi (2002) insist, a good paraphrase has no intrinsic direction. If sentence $\mathrm{A}$ can be adequately paraphrased by sentence $\mathrm{B}$, then sentence B may be adequately paraphrased by sentenced A. Which of the two sentences, then, is fundamental, i.e. captures the "ontological commitments" of both sentences, to use Quine's expression? It is of course possible to choose one way or the other, depending on one's ontological preferences. However, in line with what was said above, we think it better, as a semantician, to remain in a position of metaphysical neutrality. Even if two sentences are adequate paraphrases of one another, there is no need to reduce one to the other. It suffices to explain what the meaning of each is, and how these meanings are related, in a way that ensures that both sentences are true in the same situations. Indeed, identity of truth conditions does not imply identity of sense!

In brief, we take it that reference is not illusory, at least not in the sense intended by the reductionist. A sentence where an expression like Julie's wisdom occurs refers, or makes as if to refer, to some entity, thereby introducing 
a referent in the discourse. For the semantic machinery of language, whether this entity is ultimately real or not makes no difference.

\subsection{What do derived mass nouns refer to?}

At this point, let us indicate a variety of positions that are logically possible concerning the reference of derived mass nouns.

Definite descriptions like Julie's wisdom and Julie's love for Tom

A) have no fixed meaning: it is only the linguistic and extra-linguistic context that allows us to interpret them;

B) have fixed meanings: they are ambiguous;

C) have one fixed meaning: they really or primarily refer to entities of a certain type, but they may be coerced to refer to entities of another type in certain contexts; thus, they really or primarily refer to:

C.1) facts;

C.2) degrees (Tovena, 2001) ${ }^{9}$;

C.3) instances of properties (Nicolas, 2002a, 2002b, 2004; Moltmann, 2004) $)^{10}$;

C.4) states (Parsons, 1990; Asher, 1993).

Approach A) denies that an expression like Julie's wisdom has any fixed meaning or meanings. A noun like wisdom or love is derived from an adjective or a verb. On this approach, the derivation would have no systematic effect. It would be only in the context of a specific utterance that the expression could be understood. This understanding would involve finding, given the context, an appropriate paraphrase that uses the original adjective or verb. With respect to the ontological attitudes evoked earlier, this approach may seem congenial to reductionism, and perhaps also to fictionalism. It may also be seen as a purely linguistic thesis concerning the interpretation of conversions of a gradable adjective or verb into a noun. However, the intuitions evoked in section 2.1 are much more systematic than this position predicts them to be. Approach A),

9. Tovena does not take into consideration definite uses and so does not try to account for them. But her remarks (Tovena, 2001: 575) suggest that she would agree to say that derived mass nouns like wisdom denote degrees. Let us also mention that Tovena is concerned with a class of nouns that is not exactly identical to ours. She considers what Van de Velde (1995) calls intensive nouns. These nouns are characterized semantically, by the fact that their quantification does not concern a quantity of matter or time, but intensity. Expressions like love and respect are thus included in this semantic class. So are nouns derived from gradable adjectives, like wisdom and sadness. But nouns derived from verbs denoting processes, like work and sleep, are not, since, according to Van de Velde, their quantification concerns a quantity of time.

10. Of course, several philosophers have also defended this view; see for instance, Mulligan et al. (1984) and Lowe (1998). 
which says that the interpretation of derived mass nouns is a function of the semantic and pragmatic context, thus appears to be empirically inadequate.

Approach B) claims that an expression like Julie's wisdom or Julie's love for Fred has several meanings: it is ambiguous between various types of interpretations, perhaps in terms of facts, degrees, and instances of properties. It can be contrasted with approach $\mathrm{C}$ ), which claims that these expressions primarily refer to entities of a certain type (they are not ambiguous), but they may be coerced to refer to entities of another type in certain contexts.

How can we adjudicate between ambiguity versus a primary meaning sometimes supplemented by coercion? Both approaches are consistent with the data, and so the choice is a difficult one. For the sake of simplicity, we adopt approach C.3): derived mass nouns are not ambiguous, and they refer to instances (i.e. concrete manifestations) of properties or relations. Let us see how this hypothesis accounts for our intuitions concerning the interpretations of derived mass nouns. We saw that different types of paraphrases were available depending on the type of predicate used in the sentence. This can now be explained:

- Predicates like to surprise in Julie's love for Tom surprised Fred: something may surprise us for a variety of reasons. It may surprise us because of its mere existence (this corresponds to the paraphrase in terms of a fact: the fact that Julie loved Fred surprised Tom), because of its position with respect to a certain ordering (this corresponds to the paraphrases in terms of a "degree": Tom was surprised by how wise Julie was, the degree at which Julie loved Fred surprised Tom), or because of something else. ${ }^{11}$ All these cases are thus covered in a simple and uniform way (with no coercion taking place here) if we hypothesize that the subject of to surprise is an instance of a property, an instance of love.

- Predicates like to acknowledge in Fred finally acknowledged Julie's love for Tom: the verb requires its direct object to denote a fact, as evidenced by the following example: John acknowledged the problem, which means that John acknowledged the fact that the problem existed. In these two examples, it is therefore plausible to hypothesize that coercion is taking place: the meaning of the direct object of the verb is coerced, so that it receives, in this context, a novel interpretation in terms of a fact. ${ }^{12}$

11. Zucchi (1993: 184) makes a similar remark concerning the alleged ambiguity of a sentence like Mary's resignation surprised us, often claimed to have an event reading and a fact reading.

12. Asher (1993: 159, 162) holds a similar view. He takes a derived nominal like the collapse of the Germans to denote primarily an event, but to take on a new meaning, in terms of a fact, in contexts like: The collapse of the Germans is a fact. Likewise, he takes an expression like John's honesty to denote primarily a state, but to take on a new meaning in a context like John's honesty is well known. 
- Predicates like to describe in Fred described Julie's love for Tom: by hypothesis, an expression like Julie's love for Tom denotes an instance of love, a concrete manifestation of a property. It is therefore something that can be described (or, say, admired).

- Predicates like greater than in Julie's love for Tom was greater than her love for Fred: this sentence compares two instances of love using an ordering relation associated with the adjective great. Given the vague meaning of great, this may then be understood as comparing the two instances of love using the ordering relation associated with the noun love and the verb to love. Hence the possibility of a paraphrase using the term degree: the degree at which Julie loved Tom was greater than the degree at which she loved Fred.

- Predicates like to last in Julie's love for Tom lasted half a year: an instance of a property is a concrete entity, a concrete manifestation of a property. It can subsist over time, hence the possibility of employing the predicate to last. ${ }^{13}$

Let us now see how the distributive, collective, and intermediate construals of concrete mass nouns and plurals may be accounted for. We will then see how gradability can be modelled. This will complete our discussion of the theoretical foundations needed in order to provide a complete semantics for derived mass nouns. We will make this semantics explicit in section 4.

\subsection{Distributive, collective, and intermediate construals of concrete mass nouns and plurals}

Take a concrete mass noun like wine or furniture. Definite descriptions, like the wine, can be used to refer to entities of certain kind. This can be accounted for by saying that a noun like wine denotes entities of a certain kind, namely, instances of wine. This also explains the interpretation of indefinite descriptions like some wine, which are taken to quantify existentially over instances of wine.

Moreover, sentences where a concrete mass noun or a plural appears may receive distributive, collective, and intermediate construals. This can be accounted for by positing, with Gillon (1990, 1992, 1996), a certain rule for the interpretation of simple clauses. Gillon's account has two main assets. First, contrary to other authors (e.g. Link, 1983; Landman, 1989), Gillon postulates no hidden operator in order to derive these construals: this is done by a rule

13. Asher $(1993,162)$ suggests that in such sentences, Julie's love for Tom refers to a state that lasts for a certain period. However, states can be seen as special cases of instances of properties or relations: if there is a state that corresponds to Julie's love for Tom, then this state would seem to be an instance of love, an instance of a property or relation. The notion of an instance of a property or relation thus appears to be more general than the notion of a state, also encompassing processes and events as special cases (Mulligan, 1999: 170). 
for the interpretation of simple clauses, like The furniture is in these rooms. Second, this is easily generalized to other cases, which show a similar behavior, notably complex noun phrases containing a preposition, like the furniture in these rooms (Gillon, 1996). To derive the conditions of application of such complex noun phrases, other theories have to postulate more hidden machinery, something that is undesirable since it can be prevented.

Let us see how Gillon's account works. We follow him quite closely, but introduce a few technical modifications to ensure that everything works nicely for both plurals and mass nouns. We begin, for ease of exposition, with the case of plural count nouns. Suppose that, in a given circumstance, there are only three men we can talk about: a, b, and c. Then the denotation of the singular count noun man in the circumstance is $[\mathrm{man}]=\{\mathrm{a}, \mathrm{b}, \mathrm{c}\}$, while the denotation of the plural count noun men is [men] $=\{\mathrm{a}, \mathrm{b}, \mathrm{c}, \mathrm{a}+\mathrm{b}, \mathrm{b}+\mathrm{c}, \mathrm{c}+\mathrm{a}, \mathrm{a}+\mathrm{b}+\mathrm{c}\}$. The sign ' + ' is used for mereological sums. Thus, $a+b+c$ is the mereological sum of $\mathrm{a}, \mathrm{b}$ and c. $\mathrm{a}+\mathrm{b}+\mathrm{c}$ can be thought of as $\mathrm{a}, \mathrm{b}$ and $\mathrm{c}$ taken together. Since $\mathrm{a}, \mathrm{b}$ and $c$ are concrete objects (each is a man), their sum is also a concrete object. (For more on mereology, see Simons, 1987.)

Mereology allows us to represent collective construals easily. If a man $\mathrm{b}$ carries a piano $\mathrm{p}$, we may represent that as $\mathrm{C}(\mathrm{b}, \mathrm{p})$, where $\mathrm{C}$ corresponds to the relation of carrying. If three men $\mathrm{a}, \mathrm{b}$ and $\mathrm{c}$ jointly carry a piano $\mathrm{p}$, we may represent that as $\mathrm{C}(\mathrm{a}+\mathrm{b}+\mathrm{c}, \mathrm{p})$ : the relation $\mathrm{C}$ holds between $\mathrm{a}, \mathrm{b}$ and $\mathrm{c}$ taken together $(a+b+c)$ and $p$. This is not enough, however, as intermediate construals must also be accounted for. To do so, we need a notion of $M$-covering. (Gillon uses a notion of aggregation, which is defined a bit differently. The difference is purely technical; both notions play exactly the same role.)

Let $M$ be a plural count noun or a singular mass noun. A set $\mathrm{X}$ is an $M$-covering of a set $\mathrm{Z}$ if and only if these two conditions are satisfied:

i) $\mathrm{X}$ is a subset of the denotation of $M: \mathrm{X} \subseteq[M]$

ii) The mereological sum of the elements of $X$ is identical to the mereological sum of the elements of $Z$.

For example, in the situation described just earlier, the denotation of the plural count noun men was $\{\mathrm{a}, \mathrm{b}, \mathrm{c}, \mathrm{a}+\mathrm{b}, \mathrm{b}+\mathrm{c}, \mathrm{c}+\mathrm{a}, \mathrm{a}+\mathrm{b}+\mathrm{c}\}$, and the denotation of these men was $\{\mathrm{a}+\mathrm{b}+\mathrm{c}\}$. The set $\mathrm{X}=\{\mathrm{a}+\mathrm{b}, \mathrm{b}+\mathrm{c}\}$ is a men-covering of [these men] since $\mathrm{X}$ is included in $[$ men] and $(\mathrm{a}+\mathrm{b})+(\mathrm{b}+\mathrm{c})=\mathrm{a}+\mathrm{b}+\mathrm{c}$.

Take now a sentence like:

These men carried these pianos.

«The essential idea is that a predicate is evaluated, not with respect to the denotation of a [...] noun phrase which is its argument, but with respect to the elements in a [covering] constructed from the [...] noun phrase's denotation, where the choice of [covering] is determined by one's knowledge of the world and one's context » (Gillon 1996: 461). Since the sentence (48) contains two 
plural noun phrases, two coverings must be chosen. Let $\mathrm{X}$ be the chosen mencovering of [these men], and $\mathrm{Y}$ the chosen pianos-covering of [these pianos]. Then the sentence is true, relative to this choice of coverings, if and only if:

- for all $\mathrm{x}$ in $\mathrm{X}$, there is a $\mathrm{y}$ in $\mathrm{Y}$ such that $\mathrm{C}(\mathrm{x}, \mathrm{y})$;

- for all $\mathrm{y}$ in $\mathrm{Y}$, there is an $\mathrm{x}$ in $\mathrm{X}$ such that $\mathrm{C}(\mathrm{x}, \mathrm{y})$.

Suppose that in (48), these men denotes $\{\mathrm{a}+\mathrm{b}+\mathrm{c}\}$ and these pianos denotes $\{\mathrm{p}+\mathrm{q}\}$. Let the chosen coverings be $\mathrm{X}=\{\mathrm{a}, \mathrm{b}+\mathrm{c}\}$ and $\mathrm{Y}=\{\mathrm{p}, \mathrm{q}\}$. Then the sentence is true if either $\mathrm{C}(\mathrm{a}, \mathrm{p}) \wedge \mathrm{C}(\mathrm{b}+\mathrm{c}, \mathrm{q})$, i.e. a carried $\mathrm{p}$ while $\mathrm{b}$ and $\mathrm{c}$ carried q together, or $\mathrm{C}(\mathrm{a}, \mathrm{q}) \wedge \mathrm{C}(\mathrm{b}+\mathrm{c}, \mathrm{p})$.

Finally, consider:

These men carried this furniture.

The direct object of to carry is the mass noun phrase this furniture. Suppose the furniture present in the circumstance is a desk $\mathrm{d}$, a lamp 1 and a table t. Then the denotation of furniture is $\{\mathrm{d}, \mathrm{l}, \mathrm{t}, \mathrm{d}+\mathrm{l}, \mathrm{l}+\mathrm{t}, \mathrm{t}+\mathrm{d}, \mathrm{d}+\mathrm{l}+\mathrm{t}\}$, while the denotation of this furniture is $\{\mathrm{d}+\mathrm{l}+\mathrm{t}\}$. The rule of interpretation given above applies, and yields a similar range of construals as for the sentence These men carried these pianos.

For the moment, we have only considered simple clauses containing a verb. However, as shown by Gillon (1996), and as seen in section 2.5, there are other complex expressions that express a predication. This is the case in particular of complex noun phrases containing prepositions, like the children of these people. Here, the preposition of expresses a relation $\mathrm{O}$ (the relation of being a child of) that holds between some of the children and some of the people. The denotation of the complex noun phrase depends on the denotation of the second argument of the preposition (these people). In parallel with the rule for simple clauses, Gillon (1996: 465) proposes the following rule of interpretation for such complex noun phrases.

The denotation $\mathrm{D}$ of the children of these people is the set containing the largest mereological sum of children such that there is a children-covering $\mathrm{X}$ over D and a people-covering Y over [these people] satisfying the conditions:

- for all $\mathrm{x}$ in $\mathrm{X}$, there is a $\mathrm{y}$ in $\mathrm{Y}$ such that $\mathrm{O}(\mathrm{x}, \mathrm{y})$;

- for all $\mathrm{y}$ in $\mathrm{Y}$, there is an $\mathrm{x}$ in $\mathrm{X}$ such that $\mathrm{O}(\mathrm{x}, \mathrm{y})$.

Suppose for instance that these people denotes $\mathrm{Y}=\{\mathrm{p}+\mathrm{q}+\mathrm{r}\}$, and that $\mathrm{p}$ and $\mathrm{q}$ have, together, one child $\mathrm{a}$, while $\mathrm{r}$ has two children, $\mathrm{b}$ and $\mathrm{c}$. Then, the denotation of the children of these people is $\mathrm{D}=\{\mathrm{a}+\mathrm{b}+\mathrm{c}\}$. This is indeed the largest sum of children that satisfies the conditions above. It does so in the following way: the children-covering $\mathrm{X}$ over $\{\mathrm{a}+\mathrm{b}+\mathrm{c}\}$ is $\{\mathrm{a}, \mathrm{b}, \mathrm{c}\}$, the peoplecovering $\mathrm{Y}$ over $\{\mathrm{p}+\mathrm{q}+\mathrm{r}\}$ is $\{\mathrm{pq}, \mathrm{r}\}$, and we have: $\mathrm{O}(\mathrm{a}, \mathrm{pq}) \wedge \mathrm{O}(\mathrm{b}, \mathrm{r}) \wedge \mathrm{O}(\mathrm{c}, \mathrm{r})$.

The same rule of interpretation applies for instance to the furniture in these rooms, with the relation of being in.

Let us now turn to the issue of modeling gradability. 


\subsection{Gradability}

In all the major parts of speech, we find expressions that are gradable, i.e. expressions that accept the comparatives more and less. How should we account for gradability? Semantically, what is the common core behind all instances of gradability? And beyond this common core, are they notable semantic differences, so that more specific mechanisms are operating in certain uses of gradable predicates? (The research on gradability has focused on gradable adjectives. For reviews of the literature, see particularly von Stechow (1984) and Klein (1991), as well as Kennedy (1999) and Kennedy \& McNally (2005).)

We find gradable expressions among:

- plural count nouns (more cats), but not singular count nouns (*more cat)

- mass nouns, be they concrete (more wine, less furniture), or derived (more sadness, less love, more work);

- adjectives: taller, less sad;

- verbs: to love less, to work more.

While all plural count nouns and all mass nouns are gradable, this is neither the case for all common nouns (*more immortality, ${ }^{*}$ more immortalities), nor for all adjectives (*more immortal), nor for all verbs (*to die more).

With respect to gradability, the following uses of gradable predicates are especially important to consider:

- comparative uses ( $c f$. above);

- modified uses:

* imprecise: many cats, much wine, a lot of wisdom, very wise, to love a lot, to work much;

* precise: only some gradable predicates have what we call a precise modified use, a use where a precise measure is made: two cats, three liters of wine, four pieces of furniture, to work five hours;

- unmodified uses, where the predicate is used by itself: Cats were fighting in the street; John drank wine; Julie showed wisdom; Julie loved Fred; Julie worked.

The interpretation of these uses can be roughly described as follows.

- Comparative uses: an ordering (possibly incomplete) is imposed on objects according to whether one object possesses the relevant property to greater or less extent than another ( $c f$. Klein, 1991).

- Unmodified uses: the predicate attributes a property to its argument(s). In most cases, this property is fixed (cats, wine, furniture, to love, love, to work, work, sad, sadness); in other cases (tall, wise, wisdom), this property depends on context. 
Let us comment on this distinction (which concerns expressions used literally). In many cases, it is clear that there is no context dependence. Thus, whether something is wine or not is independent of context; so is whether Julie works or not (if the expression is used literally); whether she is sad or not; and whether she loves Bill or not. On the contrary, whether Julie is tall or not depends on context. It depends on how tall is understood: $e$.g., is she tall for a ten-year-old girl, or tall for a professional basketball player? Similarly, is Fred wise for kid, or wise for a French man? The following contrasts confirm this distinction.

(50) ?? Fred is sad for a kid.

(51) ?? Fred felt sadness for a kid.

(52) ?? Fred loved Mary for a friend.

(53) ?? Fred showed love for Mary for a friend.

(54) Fred is tall for a kid / for a French man.

(55) Fred is wise for a kid / for a French man.

(56) Fred showed wisdom for a kid / for a French man.

It seems that the gradable predicates whose unmodified use is interpreted in a contextually dependent manner come (mostly or all) from a subset of gradable adjectives (tall, wise), or are derived from these (wisdom). (In his work on gradable adjectives, Kennedy has made extensive use of this distinction; $c f$. for instance Kennedy \& McNally (2005). He uses the terms relative and absolute, relative gradable adjectives being those whose unmodified use is interpreted in a contextually dependent manner.)

- Modified uses:

* Imprecise: an object is said to possess a property to a certain extent, which is indicated only imprecisely, and in a manner that crucially depends on context ( $c f$. work a lot); the object is thus said to belong to a contextually determined set.

* Precise: an object is said to possess a property to a precisely measured extent.

Let us now see how we can model the interpretation of these uses. Our aim is to identify the simplest logical apparatus that is conceptually needed. Any analysis (even if it uses stronger mechanisms) will then have to yield truths conditions that will be equivalent with these at some level.

- Comparative uses: the simplest way to account for them is to say that a gradable predicate $\mathrm{P}$ has an associated (possibly incomplete) order relationship $>_{\mathrm{P}}$, and that the comparative use of the predicate $\mathrm{P}$ orders two entities, $\mathrm{x}$ and $\mathrm{y}$, in a certain way: $\mathrm{x}>_{\mathrm{P}} \mathrm{y}$ in the case of more $P(e . g . \mathrm{x}$ is more wine than $\mathrm{y} ; \mathrm{x}$ 
is taller than $\mathrm{y})$, and $\mathrm{x}<_{\mathrm{P}} \mathrm{y}$ in the case of less $P(e . g . \mathrm{x}$ is less wine than $\mathrm{y}$; $\mathrm{x}$ is less tall than $\mathrm{y}$ ). When the predicate has several arguments, like the transitive verb to love, it is ordered pairs of entities that are ordered by $>_{\mathrm{p}}$ : Julie loves Fred more than Bill corresponds to $(\mathrm{j}, \mathrm{f})>_{\text {love }}(\mathrm{j}, \mathrm{b})$.

- Unmodified uses: when we focus on the majority of cases, that is, on predicates whose interpretation is not contextually dependent (cats, wine, furniture, sad, sadness, to love, love, to work, work), the simplest way to account for their unmodified use is to model them as denoting a contextually independent set $\mathrm{S}$. Or equivalently, as denoting a function from entities to truth-values, e.g. wine (x) for the noun wine, and love $(\mathrm{x}, \mathrm{y})$ for the verb to love. When we turn to those cases where the interpretation is contextually dependent, it is then quite natural to model them as denoting a set that is contextually determined. Or equivalently, as denoting a function from contexts $\mathrm{c}$ and entities $\mathrm{x}$ to truth-values, e.g. tall $(\mathrm{c}, \mathrm{x})$ for the adjective tall. (This is the basis of the strategy followed by Klein, 1980.)

- Modified uses:

* Imprecise: as above, let $\mathrm{S}$ be the (contextually dependent or independent) set determined by the bare use of the gradable predicate in the context of speech, c. An imprecise modified use contextually determines a subset $S$ ' of $S$, with additional constraints that depend on the meaning of the modifier. For instance, a lot of wine will, in a given context $\mathrm{c}$, denote a subset S' of the set $S$ of instances of wine. S' will consist of all the instances of wine that can be described as a lot of wine in this context. (The following constraint must be respected for a lot of wine: if $\mathrm{x}$ is in $\mathrm{S}$ ' (i.e. $\mathrm{x}$ is a lot of wine) and $\mathrm{y}$ is in $\mathrm{S}$ but not in $\mathrm{S}^{\prime}$ (i.e. $\mathrm{y}$ is wine but not a lot of wine), then $\mathrm{x}>_{\text {wine }} \mathrm{y}$.) Equivalently, we may see $a$ lot of wine as corresponding to a function a-lot-of-wine from contexts $\mathrm{c}$ and instances of wine $\mathrm{x}$ to truth-values. And this function may be seen as the result of applying a function a-lot-of to the function wine: a-lot-ofwine $(\mathrm{c}, \mathrm{x})=[\mathrm{a}-$ lot-of $($ wine $)](\mathrm{c}, \mathrm{x})$.

* Precise: in these cases, a precise measure is made. This measure is not contextually dependent. This can be represented using a measure function. Two liters of wine will denote a subset S' of $\mathrm{S}$, such that any member $\mathrm{x}$ of $\mathrm{S}$ ' can be said to be two liters of wine. That is, we have something like: [liters$\operatorname{of}($ wine $)](x)=2$, where liters-of(wine) is a function from instances of wine to positive real numbers, which measures them in liters. Likewise, six feet tall will denote a subset $S^{\prime}$ of $S$, such that any member $x$ of $S^{\prime}$ can be said to be six feet tall, i.e. [feet(tall)] $(\mathrm{x})=6$, where feet(tall) is a function that measures, in feet, how tall $\mathrm{x}$ is. Finally, to work two hours will denote a subset $\mathrm{S}$ ' of $\mathrm{S}$, such that any member $\mathrm{x}$ of $\mathrm{S}$ ' can be said to work two hours, i.e. [hours(work)] $(x)=2$, where hours(work) if a function that measures, in hours, the amount of time worked by $\mathrm{x}$. 
Let us summarize what these assumptions give us for some of the gradable predicates considered above:

cats: ${ }^{14}$

$\mathrm{x}$ are cats: cats(x)

$\mathrm{x}$ are more cats than $\mathrm{y}: \mathrm{x}>_{\text {cats }} \mathrm{y}$

$\mathrm{x}$ are a lot of cats: [a-lot-of(cats)](c,x)

$\mathrm{x}$ are two cats: [number(cats)] $(\mathrm{x})=2$

(58) wine:

$\mathrm{x}$ is wine: wine $(\mathrm{x})$

$\mathrm{x}$ is more wine than $\mathrm{y}: \mathrm{x}>$ wine $\mathrm{y}$

$\mathrm{x}$ is a lot of wine: [a-lot-of(wine)](c,x)

$\mathrm{x}$ is two liters of wine: [liters(wine) $](\mathrm{x})=2$

(59) sad:

$\mathrm{x}$ is $\operatorname{sad}: \operatorname{sad}(\mathrm{x})$

$\mathrm{x}$ is more sad than $\mathrm{y}$ : $\mathrm{x}>_{\text {sad }} \mathrm{y}$

$\mathrm{x}$ is very sad: [very $(\mathrm{sad})](\mathrm{c}, \mathrm{x})$

(60) tall:

$\mathrm{x}$ is tall: tall( $(\mathrm{c}, \mathrm{x})$

$\mathrm{x}$ is taller than $\mathrm{y}: \mathrm{x}>_{\text {tall }} \mathrm{y}$

$\mathrm{x}$ is very tall: [very $($ tall $)](\mathrm{c}, \mathrm{x})$

$\mathrm{x}$ is six feet tall: [feet(tall)]( $\mathrm{x})=6$

(61) to love:

$\mathrm{x}$ loves $\mathrm{y}$ : love $(\mathrm{x}, \mathrm{y})$

$\mathrm{x}$ loves $\mathrm{y}$ more than $\mathrm{z}:(\mathrm{x}, \mathrm{y})>_{\text {to love }}(\mathrm{x}, \mathrm{z})$

$\mathrm{x}$ loves y a lot: $[\mathrm{a}-\operatorname{lot}($ love $)](\mathrm{c}, \mathrm{x}, \mathrm{y})$

(62) to work:

$\mathrm{x}$ works: work $(\mathrm{x})$

$\mathrm{x}$ works more than $\mathrm{y}: \mathrm{x}>_{\text {to work }} \mathrm{y}$

$\mathrm{x}$ works a lot: [a-lot(work)](c,x)

$\mathrm{x}$ works two hours: [hours (work)] $(\mathrm{x})=2$

Let us make several comments. Conceptually, we think it is important to identify the simplest logical apparatus that is needed to account for each type of use of a gradable predicate. Any analysis of gradable predicates will then have to incorporate this logical apparatus in one way or another. And if it uses stronger mechanisms, it will have to provide justifications for doing so.

The literature on gradability has focused on gradable adjectives. It has thereby approached gradability from a standpoint that is not general enough. In

14. We do not indicate here the connections with the singular, cat, and so leave the predicate 'cats' unanalyzed. 
the studies on gradable adjectives, it has now become customary to make use of measure functions and degrees in order to represent all the uses of gradable adjectives. This is, in effect, adopting the strategy of generalizing to the worst case (a strategy adopted explicitly by von Stechow, 1984: 53): since precise modified uses require a mechanism that makes a precise measure (a measure function), this strong apparatus is used to account for all the uses of gradable adjectives.

However, systems of precise measurement are a rather recent invention in the history of humankind. There have existed languages that did not express any precise measurement, besides elementary counting. In some languages, elementary counting reduces to making a distinction between, e.g., one, two, three, many (Greenberg, 1972). Precise modified uses are therefore restricted to uses like one cat, two cats, three cats. To model the semantics of gradable predicates in these languages, there is no need of measure functions besides a rudimentary cardinality function corresponding to one, two and three.

A similar case can be made concerning the conceptual development of children. Young children cognitively distinguish simple cardinalities. They are also able to perceive that one person is taller than another is, and can thus understand a claim like I am taller than Bill. But they do not see, nor say, that one person is six feet tall: precise measurement is a late achievement, both in cognition and in speech.

Moreover, the notion of degree is appealing only in the case of predicates that have precise modified uses (e.g. six feet tall), that is, in the case of predicates for which a precise system of measurement has been developed. In other cases, what can it mean? For instance, what can it mean to say that John is sad to degree d? No system for measuring precisely how sad people are is likely to be forthcoming. Therefore, as pointed out in their own ways by Creswell (1976) and Klein (1991), to say that John is sad to degree d is only a roundabout way of saying the following. The gradable predicate sad has an associated (perhaps incomplete) ordering relation, so that a person may be said to be sadder than another. One may form equivalence classes based on this ordering relation: two persons $\mathrm{x}$ and $\mathrm{y}$ are in the same equivalence class if and only if $\mathrm{x}$ is as sad as y, and $\mathrm{y}$ is as sad as x. Formally, a degree may be seen as such an equivalence class. Then, to say that John is sad to degree $\mathrm{d}$ is to say that John belongs to a certain equivalence class, d, with respect to the ordering relation associated with the gradable predicate sad. This can be done, but, as pointed above, there is no need of doing so, and degrees are cognitively implausible for young children, or for speakers of a language that can only express elementary counting.

For all these reasons, we have followed the strategy indicated above, namely, that of identifying the simplest logical apparatus that is needed to account for each type of use of a gradable predicate. (This is only a beginning, 
of course: much more detailed work is needed about this. And in particular, which formalism is used for such or such a construction may vary from language to language.)

A final remark is in order. The notion of gradability, which applies to the members of various lexical categories, is a very general one: a sentence containing more or less is used to make a comparison between some entities. How this comparison is then made depends on the nature of the gradable predicate (plural count noun, mass noun, adjective, verb). In particular, it may depend on the type of the verb. Thus, with verbs denoting processes (to work), what is compared is the duration of the process. Not so with verbs denoting emotions (to love), where what is compared is the intensity of the emotions felt. These particularities are also observed with the mass nouns derived from those verbs ( $c f$. Van de Velde, 1995; Nicolas, 2002a).

We have just completed the discussion of the theoretical foundations for a semantics of derived mass expressions. We can now put together the pieces of the puzzle.

\section{The semantics of derived mass expressions}

\subsection{Reference in possessive and definite uses}

Consider the sentence:

(63) Julie's love for Tom surprised Fred.

Its subject has the same meaning as the expression the love of Julie for Tom. An element of definiteness is thus part of the meaning of Julie's love for Tom. We take this element to be provided by an implicitly present iota operator. The expression Julie's love for Tom uniquely identifies a certain instance of love. In a model where the referents of Julie, Tom and Fred are j, $\mathrm{t}$ and $\mathrm{f}$ respectively, its conditions of application are:

(64) Julie's love for Tom: ip [love'( $\mathrm{p}, \mathrm{j}, \mathrm{t})]$

(We distinguish the function corresponding to the noun love, which we note love', from the function corresponding to the verb to love, which we note love.) And the truth-conditions of the sentence are:

(65) Julie's love for Tom surprised Fred is true if and only if surprised(tp [love'(p,j,t)], f)

Similarly with a noun like sadness, derived from a gradable adjective:

(66) Julie's sadness surprised Tom is true if and only if $\operatorname{surprised}(\mathrm{tp}[\operatorname{sadness}(\mathrm{p}, \mathrm{j})], \mathrm{t})$ 


\subsection{Distributive, collective, and intermediate construals}

One of the assets of Gillon's account is that applies easily to predications internal to noun phrases, in complex noun phrases like the children of these people or the furniture in these rooms (Gillon, 1996). His account may also be applied to complex noun phrases containing derived mass nouns, as we will now see on one example. For simplicity, we concentrate on what we take to be the primary reading of such noun phrases, namely, the reading in terms of instances of properties.

Consider the sentence: The strength of these men is impressive, said when watching a game opposing two teams of two people each. The interpretation of the unmodified use of each gradable predicate, strength and impressive, depends on context. Let these men denote $\{\mathrm{e}+\mathrm{f}+\mathrm{g}+\mathrm{h}\}$. Suppose that, in the context of speech $\mathrm{c}$, the men e and f, together, are strong, but they are not so individually, or this is irrelevant. Likewise, imagine that in the same context of speech, the men $\mathrm{g}$ and $\mathrm{h}$, together, are strong. In this context of speech $\mathrm{c}$, one could thus speak of the strength of $e$ and $f$; this would refer to a certain instance of strength, p, which satisfies: strength $(\mathrm{c}, \mathrm{p}, \mathrm{e}+\mathrm{f})$. Likewise, one could speak of the strength of $g$ and $h$, referring to an instance of strength q, which satisfies: strength $(\mathrm{c}, \mathrm{q}, \mathrm{g}+\mathrm{h})$.

In this context, what is the denotation of the strength of these men? According to the rule of interpretation given by Gillon, it is the set D containing the largest sum of instances of strength such that there is a strength-covering $\mathrm{X}$ over D and a men-covering Y over [these men] satisfying the two conditions:

- for each $\mathrm{x}$ in $\mathrm{X}$, there is a $\mathrm{y}$ in $\mathrm{Y}$ such that $\operatorname{strength}(\mathrm{c}, \mathrm{x}, \mathrm{y})$;

- for each $\mathrm{y}$ in $\mathrm{Y}$, there is an $\mathrm{x}$ in $\mathrm{X}$ such that $\operatorname{strength}(\mathrm{c}, \mathrm{x}, \mathrm{y})$.

We obtain the following. The denotation of the strength of these men is $\mathrm{D}=\{\mathrm{p}+\mathrm{q}\}$, the strength-covering $\mathrm{X}$ over $\mathrm{D}$ is $\{\mathrm{p}, \mathrm{q}\}$, the men-covering $\mathrm{Y}$ over [these men] is $\{\mathrm{e}+\mathrm{f}, \mathrm{g}+\mathrm{h}\}$, and we have: $\operatorname{strength}(\mathrm{c}, \mathrm{p}, \mathrm{e}+\mathrm{f}) \wedge \operatorname{strength}(\mathrm{c}, \mathrm{q}, \mathrm{g}+\mathrm{h})$. $\mathrm{p}+\mathrm{q}$ is indeed the largest sum of instances of strength that satisfies the conditions above.

Finally, the whole sentence, The strength of these men is impressive, is made true by the fact that: impressive $(\mathrm{c}, \mathrm{p}) \wedge$ impressive $(\mathrm{c}, \mathrm{q})$.

\subsection{Gradability}

We have indicated in section 3.5 what logical apparatus is needed to account for the main types of uses of gradable predicates. Applying this to derived mass nouns, which denote instances of properties or relations, we obtain what follows, c being the context of speech.

$$
\begin{aligned}
& x \text { felt love for } y \text { is true if and only if } \\
& \exists \mathrm{p}(\text { felt }(\mathrm{x}, \mathrm{p}) \wedge \text { love' }(\mathrm{p}, \mathrm{x}, \mathrm{y}))
\end{aligned}
$$


(68) $x$ felt a lot of love for $y$ is true if and only if

$\exists \mathrm{p}\left(\right.$ felt $(\mathrm{x}, \mathrm{p}) \wedge\left[\mathrm{a}-\operatorname{lot}\left(\right.\right.$ love' $\left.\left.\left.^{\prime}\right)\right](\mathrm{c}, \mathrm{p}, \mathrm{x}, \mathrm{y})\right)$

(69) $x$ felt more love for $y$ than for $z$ is true if and only if

$\exists \mathrm{p} \exists \mathrm{q}\left(\right.$ felt $(\mathrm{x}, \mathrm{p}) \wedge$ felt $(\mathrm{x}, \mathrm{q}) \wedge \operatorname{love}^{\prime}(\mathrm{p}, \mathrm{x}, \mathrm{y}) \wedge$ love' $\left.(\mathrm{q}, \mathrm{x}, \mathrm{z}) \wedge \mathrm{p}>_{\text {love }} \mathrm{q}\right)$

(70) $x$ felt sadness is true if and only if

$\exists \mathrm{p}(\operatorname{felt}(\mathrm{x}, \mathrm{p}) \wedge \operatorname{sadness}(\mathrm{p}, \mathrm{x}))$

(71) $x$ felt a lot of sadness is true if and only if

$\exists \mathrm{p}($ felt $(\mathrm{x}, \mathrm{p}) \wedge[\mathrm{a}-$ lot-of(sadness $)](\mathrm{c}, \mathrm{p}, \mathrm{x})$ )

(72) $x$ felt more sadness than $y$ is true if and only if

$\exists \mathrm{p} \exists \mathrm{q}\left(\operatorname{felt}(\mathrm{x}, \mathrm{p}) \wedge \operatorname{felt}(\mathrm{y}, \mathrm{q}) \wedge \operatorname{sadness}(\mathrm{p}, \mathrm{x}) \wedge \operatorname{sadness}(\mathrm{q}, \mathrm{y}) \wedge \mathrm{p}>_{\text {sadness }} \mathrm{q}\right)$

\subsection{The links between derived mass noun and verb or adjective}

These can now be stated. We indicate what the logical links are, which relate directly the functions and ordering relations associated with the derived noun and the gradable predicate it is derived from. Such links hold between any gradable verb or adjective and the mass noun derived from it. We illustrate them on two examples, love and sadness, which take different numbers of arguments.

- Links between the functions and relations associated with the verb to love and the noun love:

$$
\begin{aligned}
& \forall \mathrm{x} \forall \mathrm{y}\left[\operatorname{love}(\mathrm{x}, \mathrm{y}) \leftrightarrow \exists \mathrm{p}\left(\operatorname{love}^{\prime}(\mathrm{p}, \mathrm{x}, \mathrm{y})\right)\right] \\
& \forall \mathrm{c} \forall \mathrm{x} \forall \mathrm{y}[\text { [a-lot }(\text { love })](\mathrm{c}, \mathrm{x}, \mathrm{y}) \leftrightarrow \exists \mathrm{p}([\mathrm{a}-\operatorname{lot}(\text { love' })](\mathrm{c}, \mathrm{p}, \mathrm{x}, \mathrm{y})) \\
& \forall \mathrm{x} \forall \mathrm{y} \forall \mathrm{z}\left[(\mathrm{x}, \mathrm{y})>_{\text {to love }}(\mathrm{x}, \mathrm{z}) \leftrightarrow \exists \mathrm{p} \exists \mathrm{q}\left(\text { love' }^{\prime}(\mathrm{p}, \mathrm{x}, \mathrm{y}) \wedge \operatorname{love}^{\prime}(\mathrm{q}, \mathrm{x}, \mathrm{z}) \wedge \mathrm{p}>_{\text {love }} \mathrm{q}\right)\right]
\end{aligned}
$$

- Links between the functions and relations associated with sad and sadness:

$$
\begin{aligned}
& \forall \mathrm{x}[\operatorname{sad}(\mathrm{x}) \leftrightarrow \exists \mathrm{p}(\operatorname{sadness}(\mathrm{p}, \mathrm{x}))] \\
& \forall \mathrm{c} \forall \mathrm{x}[\operatorname{very}(\operatorname{sad})](\mathrm{c}, \mathrm{x}) \leftrightarrow \exists \mathrm{p}([\mathrm{a}-\operatorname{lot}-o f(\operatorname{sadness})](\mathrm{c}, \mathrm{p}, \mathrm{x})) \\
& \forall \mathrm{x} \forall \mathrm{y}\left[\mathrm{x}>_{\text {sad }} \mathrm{y} \leftrightarrow \exists \mathrm{p} \exists \mathrm{q}\left(\operatorname{sadness}(\mathrm{p}, \mathrm{x}) \wedge \operatorname{sadness}(\mathrm{q}, \mathrm{y}) \wedge \mathrm{p}>_{\text {sadness }} \mathrm{q}\right)\right]
\end{aligned}
$$

\section{Conclusion}

The main question that we wanted to address in this paper was: are derived mass nouns a separate species of mass nouns, with their own semantic properties, or can a general account be proposed, which works both for concrete and derived mass nouns? We have shown that a general semantic account can indeed be proposed. This requires that three central issues be dealt with: reference; distributive, collective, and intermediate construals; and gradability. Reference is accounted for by having the noun denote entities of a certain type. Distributive, collective, and intermediate construals are accounted for 
by Gillon's rules for the interpretation of simple clauses and complex noun phrases containing a prepositional phrase. And gradability is accounted for by associating to the predicate an ordering relation and other mechanisms for certain types of uses.

When we focus on concrete mass nouns, we come up quite naturally with such answers. When we focus on derived mass nouns, we can also propose answers of the same type. But this involves first determining whether derived mass nouns refer to certain entities, and if so, to entities of which kind. Adopting the methodological stance of metaphysical neutrality, we have proposed that derived mass nouns do refer, or make as if to refer, instances of properties or relations, thereby introducing these as referents in the discourse. Their distributive, collective, and intermediate construals are then accounted for by Gillon's rule for the interpretation of complex noun phrases. And gradability is explained in terms of an ordering relation and other mechanisms that are systematically related to those of the verb or adjective the noun is derived from.

We have gone to some length to determine whether sentences with derived mass nouns are liable to distributive, collective, and intermediate construals. Indeed, such data with derived mass nouns have never been discussed. However, they are certainly important to consider, given the fact that discussion of distributive, collective, and intermediate construals has dominated most of the research on plurals and concrete mass nouns in the last twenty years. We have shown that derived mass nouns are liable to such construals. We have then shown, again in some detail, how the account proposed by Gillon (1996) for plurals and concrete mass nouns applies to derived mass nouns. Whether this was so, indeed, could not be presumed; it had to be established.

We have also discussed how gradability can be accounted for. Gradability is a general phenomenon, which concerns each major part of speech. Studies of gradability have focused on gradable adjectives, thereby approaching gradability from a standpoint that is not general enough. To account for gradability, recent studies have made uniform use of the apparatus of measure functions and degrees. We have proposed a model in which this apparatus is involved only when explicitly asked for, that is, in cases of precise modified uses (e.g. six feet tall).

\section{REFERENCES}

Alston, William (1958). Ontological commitments. Philosophical Studies 9: 8-17.

AsHer, Nicholas (1993). Reference to Abstract Object in Discourse. Dordrecht: Kluwer Academic Publishers.

BACH, Emmon (1986). Natural language metaphysics. In Marcus et al. (eds.), Logic, Methodology and Philosophy of Science VII: 573-59. Elsevier. 
Bentham, Jeremy (1842). The Works of Jeremy Bentham, Published under the Superintendence of his Executor, John Bowring, 11 vols. Edinburgh: William Tait.

CARLson, Greg (1977). Reference to Kinds in English. Doctoral dissertation, MIT.

Cresswell, Max (1976). The semantics of degree. In Partee (ed.), Montague Grammar: 261292. New York: Academic Press.

Delacruz, Enrique (1973). Factives and proposition level constructions in Montague grammar. In Partee (ed.), Montague Grammar: 177-199. New York: Academic Press.

Dummett, Michael (1973). Frege: Philosophy of Language. London: Duckworth.

GILlon, Brendan (1987). The readings of plural noun phrases in English. Linguistics and Philosophy 10: 199-219.

GiLLon, Brendan (1990). Bare plurals as plural indefinite noun phrases. In Kyburg et al. (eds.), Knowledge Representation and Defeasible Reasoning: 119-166. Netherlands: Kluwer Academic Publishers.

Gillon, Brendan (1992). Towards a common semantics for English count and mass nouns. Linguistics and Philosophy 15: 597-639.

Gillon, Brendan (1996). Collectivity and distributivity internal to English noun phrases. Language Sciences 18/1-2: 443-468.

GreEnberg, Joseph (1972 / 1990). Numeral classifiers and substantial number: Problems in the genesis of a linguistic type. Reprint in Greenberg (1990), On Language. Selected Writings of Joseph H. Greenberg. Stanford: Stanford University Press.

Kennedy, Christopher (1999). Projecting the Adjective. New York: Garland.

KenNedy, Christopher; McNally, Louise (2005). Scale structure and the semantic typology of gradable predicates. Language 81/2: 1-37.

Kiparsky, Paul; Kiparsky, Carol (1971). Fact. In Steinberg \& Jakobovits (eds.), Semantics: an Interdisciplinary Reader in Philosophy, Linguistics, and Psychology: 345-369. Cambridge: Cambridge University Press.

KLEIBER, Georges (1994). Nominales. Essais de sémantique référentielle. Paris: A. Collin.

KLEIN, Ewan (1980). A semantics for positive and comparative adjectives. Linguistics and Philosophy 4: 1-45.

KLEIN, Ewan (1991). Comparatives. In von Stechow \& Wunderlich (eds.), Semantics, an International Handbook of Contemporary Research: 673-691. Berlin: Walter de Gruyter.

KRIFKA, Manfred (1991). Massennomina. In von Stechow \& Wunderlich (eds.), Semantics, an International Handbook of Contemporary Research: 399-417. Berlin: Walter de Gruyter.

Landman, Fred (1989). Groups I. Linguistics and Philosophy 12: 559-606.

Landman, Fred (2000). Events and Plurality. London: Kluwer Academic Publishers.

Larson, Richard; Segal, Gabriel (1995). Knowledge of Meaning. Cambridge: MIT Press.

LinK, Godehard (1983). The logical analysis of plurals and mass terms: A lattice-theoretical approach. In Bauerle, Schwartze \& von Stechow (eds.), Meaning, Use and Interpretation of Language: 302-323. Berlin: Mouton de Gruyter.

Lowe, Jonathan (1998). The Possibility of Metaphysics. Oxford: Clarendon Press.

Moltmann, Friederike (2004). Two kinds of universals and two kinds of collections. Linguistics and Philosophy 27: 739-776.

Moltmann, Friederike (2007). Event, tropes and truth making. Philosophical Studies 134/3: 363-403. 
Mulligan, Kevin; Simons, Peter; Smith, Barry (1984). Truth-makers. Philosophy and Phenomenological Research XIV/3: 287-321.

Mulligan, Kevin (1999). Perception, particulars and predicates. In Fisette (ed.), Consciousness and Intentionality: Models and Modalities of Attribution. London: Kluwer Academic Publishers.

Nicolas, David (2002a). La Distinction entre noms massifs et noms comptables. Aspects linguistiques et conceptuels. Louvain: Peeters.

Nicolas, David (2002b). Do mass nouns constitute a semantically uniform class? Kansas Working Papers in Linguistics 26: 113-121.

Nicolas, David (2004). The semantics of nouns derived from gradable adjectives. In Meier \& Weisgerber (eds.), Proceedings of Sinn und Bedeutung 8. Disponible sur http:// d.a.nicolas.free.fr/papers.htm.

Parsons, Terrence (1990). Events in the Semantics of English. Cambridge: MIT Press.

Partee, Barbara (2005). Topics in Formal Semantics, Lecture 5. Course handout of the Research Seminar on Topics in Formal Semantics (MGU), http://people.umass.edu/ partee/MGU_2005/MGU055.pdf.

Pelletier, Jeffrey; Schubert, Leonard (1989). Mass expressions. In Gabbay \& Guenthner (eds.), Handbook of Philosophical Logic: 327-407. D. Reidel Publishing Company.

Rosen, Gideon (2005). Problems in the history of fictionalism. In Kalderon (ed.), Fictionalism in Metaphysics: 14-64. Oxford: Oxford University Press.

Simons, Peter (1987). Parts: a Study in Ontology. Oxford: Oxford University Press.

Tovena, Lucia (2001). Between mass and count. In Mergerdoomian \& Barel (eds.), Proceedings of WCCFL: 565-578. Medford: Cascadilla Press.

VAN DE Velde, Danièle (1995). Le Spectre nominal. Louvain: Peeters.

VARZI, Achille (2002). Words and objects. In Bottani, Carrara \& Giaretta (eds.), Individuals, Essences and Identity: 49-75. Boston: Kluwer Academic Publishers.

VendeER, Zenon (1957). Verbs and times. The Philosophical Review 66: 143-160.

Vendler, Zenon (1968). Adjectives and Nominalizations. The Hague: Mouton.

Verkuyl, Henk (1993). A Theory of Aspectuality. Cambridge: Cambridge University Press.

von STECHOw, Arnim (1984). Comparing semantic theories of comparison. Journal of Semantics 3/1-2: 1-77.

Wilkinson, Karina (1991). Studies in the semantics of generic noun phrases. Doctoral dissertation, University of Massachusetts, Amherst.

Zucchi, Alessandro (1993). The Language of Propositions and Events. London: Kluwer Academic Publishers. 


\section{RÉSUMÉ}

Quelle est la sémantique des expressions massives comme sagesse et amour, qui sont dérivées d'expressions graduables (sage, aimer)? Nous examinons d'abord comment ces expressions sont utilisées, puis comment elles sont interprétées dans leurs divers emplois. Nous montrons en particulier que, tout comme avec les noms massifs concrets ordinaires (vin, mobilier), les énoncés où elles figurent peuvent recevoir des interprétations distributives, collectives et intermédiaires. Nous proposons alors un modèle qui explique ces données, dans lequel les expressions massives dérivées dénotent des instances de propriétés. Le modèle est suffisamment général pour s'appliquer aussi bien aux noms massifs concrets qu'aux noms massifs dérivés. Ceci établit que les noms massifs ont une sémantique uniforme. Une autre caractéristique du modèle est que pour expliquer la graduabilité des expressions massives, il n'emploie degrés et fonctions de mesure que lorsque ceux-ci sont ouvertement exprimés, dans des expressions comme beaucoup de sagesse ou deux litres de vin.

\section{Mots-CLÉS}

Noms massifs, nominalisation, propriétés, graduabilité, distributivité. 